\title{
KNOWLEDGE OF THE FIRM AND THE EVOLUTIONARY THEORY OF THE MULTINATIONAL CORPORATION
}

\author{
Bruce Kogut* \\ University of Pennsylvania \\ Udo Zander** \\ Stockholm School of Economics
}

\begin{abstract}
Firms are social communities that specialize in the creation and internal transfer of knowledge. The multinational corporation arises not out of the failure of markets for the buying and selling of knowledge, but out of its superior efficiency as an organizational vehicle by which to transfer this knowledge across borders. We test the claim that firms specialize in the internal transfer of tacit knowledge by empirically examining the decision to transfer the capability to manufacture new products to wholly owned subsidiaries or to other parties. The empirical results show that the less codifiable and the harder to teach is the technology, the more likely the transfer will be to wholly owned operations. This result implies that the choice of transfer mode is determined by the efficiency of the multinational corporation in transferring knowledge relative to other firms, not relative to an abstract market transaction. The notion of the firm as specializing in the transfer and recombination of knowledge is the foundation to an evolutionary theory of the multinational corporation.
\end{abstract}

The study of the multinational corporation has tended to be divided by perspectives ranging from economics, to organizational theory, and history and politics. These perspectives are complementary insofar that the multinational corporation is an economic organization that evolves from its national origins to spanning across borders. The cornerstone of this evolutionary

*Bruce Kogut is Associate Professor at the Wharton School, University of Pennsylvania. He spent the academic year 1992-1993 as a visiting scholar at the Centre de Recherche en Gestion at the Ecole Polytechnique in Paris, France.

**Udo Zander is Assistant Professor at the Institute of International Business (IIB) at the Stockholm School of Economics. His research focuses on international strategy and management, in particular how new technology is transferred within the international firm and imitated by competitors.

We would like to thank Peter Buckley, Jean-François Hennart, Will Mitchell, Mira Wilkins, and the anonymous referees for their comments.

Received: August 1992; Revised: January \& June 1993; Accepted: June 1993. 
approach is the treatment of the firm as a social community whose productive knowledge defines a comparative advantage. ${ }^{1}$

This approach shares similarities with and is yet distinct from, the standard economic treatment of the multinational corporation. A compelling explanation for the determination of the boundaries of the firm has rested on two observations. The first is that a necessary condition for trade among firms and among countries is comparative advantage: differences in productivity in carrying out economic activities make it desirable for firms and nations to specialize and trade the products and services that reflect their superior capabilities. A second observation is that the hazard or cost of relying upon the market necessitates the "internalization" of trade (or transactions) within the firm. In the language used in the literature on foreign direct investment, the first observation concerns the ownership, or firm-specific, advantage; the latter observation concerns the "internalization" of the market. ${ }^{2}$

These two observations provide an explanation for why economic activity should be organized within a firm and why foreign direct investment should occur when trade is transacted across national boundaries. There is no logical error in this argument, but we question the necessity of the second observation. Comparative advantage is the condition governing firm trade, direct investment, and growth. The question facing the firm is whether this advantage is more economically -in terms of its costs and market effectstransferred to an affiliate subsidiary or to other firms. Hazard of the market need not be consequential in this calculation.

The question posed above presumes that the underlying knowledge can be packaged and transferred at a cost. It cannot always be. Consider the following example. Direct investment is the transfer of the organizational principles, or knowledge, of the firm from one country to another. Italy, despite its economic wealth, has a strikingly lower share of world direct investment than comparable countries. From the many studies on the more dynamic Italian regions, one can hazard the guess that outward direct investment from Italy is impeded by the difficulty of transferring knowledge grounded in the close ties within industrial and regional networks. The characteristics of social knowledge, i.e., how it is known to groups of people, influences the ability to transfer technology and, hence, direct investment flows.

We suggest in this article that the decision to transfer technology within the firm or in the market can be explained by the attributes of knowledge that constitute the ownership advantage of the firm. A firm is a repository of knowledge that consists of how information is coded and action coordinated. The mode by which technology is transferred, e.g., within the firm or by licensing to other parties, is influenced by the characteristics of the advantage that motivates the growth of the firm across borders.

The first aim of this article is to resolve the contradiction in the discussion of knowledge as a public good or as tacit by developing continuous scales 
of the underlying dimensions of codifiability, complexity, and teachability. We apply these scales to examine the proposition that the more tacit the technology, the more likely technology will be transferred within the firm. The empirical investigation focuses on what Hayami and Ruttan [1971] call "design transfer," i.e., the transfer of the capability to manufacture the product. Through questionnaires, data on the transfer of manufacturing capability to commercialize thirty-five major Swedish innovations were collected. There were eighty-two cases reported under which the technologies were transferred to countries outside Sweden. The data from the questionnaire were used to construct the scales measuring the dimensions of knowledge. By specifying a logit regression, testing the effect of these scales on the choice variable whether to transfer the technology within the firm or by license, strong support was found for the proposition that the choice of transfer mode is explained by the degree of tacitness of technology.

The second aim of this article is to question a prevailing assumption that firms exist to internalize markets. To open this line of questioning, we cite extensively from the literature on market failure and the multinational corporation to show the dominant thinking. The view we develop is that firms are social communities that serve as efficient mechanisms for the creation and transformation of knowledge into economically rewarded products and services. The relevant benchmark for whether a firm will transfer a technology internally is its efficiency in this respect relative to other firms. Market failure considerations are not required.

The primary casualty of this view is the belief that the boundaries of the firm can be explained only by the creation of governance mechanisms to curb the opportunism of individuals. It would, obviously, be a mistake to deny that opportunism has an effect on the design of contracts and firm governance. But the design of the governance mechanisms is not equivalent to the capabilities of firms and what individuals know how to do. Cooperation within an organization leads to a set of capabilities that are easier to transfer within the firm than across organizations and constitute the ownership advantage of the firm. These capabilities consist as well of the capacity to grow and develop through the recombination of existing elements of the knowledge of the firm and its members. It is this notion of the firm as a repository of social knowledge that structures cooperative action that lies at the foundation of an evolutionary theory of the multinational corporation. We turn to this latter consideration in the conclusions.

\section{DIRECT INVESTMENT AND KNOWLEDGE AS A PUBLIC GOOD}

Since the seminal thesis of Hymer [1976] was placed in the public domain in 1960, the central issue in the theory of foreign direct investment has been the nature of firm-specific advantages and their transfer across borders. A principal belief is that the primary advantage that a firm brings to foreign markets is its possession of superior knowledge. Largely, foreign direct 
investment is the transfer of an intermediate good, called knowledge, which embodies a firm's advantage, whether it be the knowledge underlying technology, production, marketing or other activities. ${ }^{3}$

This bond between direct investment and the transfer of firm-specific knowledge as an intermediate good was first made explicit in the important article by Caves [1971] which emphasized the ability to differentiate goods. He described this relationship succinctly. "Here is the link," he wrote, "to the basis for direct investment: the successful firm producing a differentiated product controls knowledge about serving the market that can be transferred to other national markets for this product at little or no cost."

It has become commonplace to append an additional condition to Caves' argument that the market for the sale of this knowledge is imperfect. ${ }^{4}$ As claimed by Johnson [1970], McManus [1972], and Magee [1977], knowledge has the property of being a public good, that is, it can be transferred at zero marginal cost. ${ }^{5}$ As a result, the firm that is responsible for its creation faces the difficulty of appropriating a return to its use.

In the landmark statement by Buckley and Casson [1976], this public good character of knowledge, which results in the two critical properties of being easily transferred and hard to protect, lies at the core of their theory of internalization. They write:

There is a special reason for believing that internalization of the knowledge market will generate a high degree of multinationality among firms. Because knowledge is a public good which is easily transmitted across national boundaries, its exploitation is logically an international operation; thus unless comparative advantage or other factors restrict production to a single country, internalization of knowledge will require each firm to operate a network of plants on a worldwide basis. ${ }^{6}$ (p. 45)

Rugman has offered the stronger proposition that the multinational enterprise (MNE) arises due to the internalization of the failure of the market for information [1980]. "There is no proper market," he writes, "for the sale of information created by the MNE and therefore no price for it ... the MNE is driven to create an internal market of its own in order to overcome the failure of an external market to emerge for the sale of information" (p. 368).

One does not need to go as far as Rugman's assertion of market failure to make the case that the multinational enterprise exists because it economizes on information. Hennart [1982], following Arrow's work [1974] on information and the organization, stresses the ability of the firm to lower search costs. While emphasizing the notion of trust, Hennart has in mind the lower incentives of employees of the same firm to cheat each other. Employees, he writes:

are not rewarded by the market value of the knowledge they sell but by their contribution to the group. Cheating would not be to their best advantage, and knowledge of this fact should facilitate the establishment of trust and reduce the cost of intrafirm information exchange. (p. 100) 
To Hennart, the costs of information exchange are inextricably linked to the problem of opportunistic behavior of the agents. ${ }^{7}$

Buckley and Casson [1976: 42ff] also stress the importance of information, but information costs are seen as handicaps to the organization and as limits on the extent to which markets can be internalized. They do not see these costs as explaining why it may be an advantage for a firm to integrate across borders. These costs are especially pertinent in limiting the growth of the firm across borders:

The personnel responsible for encoding and decoding must have similar backgrounds or operate in a similar environment, otherwise misunderstandings will arise because the implicit assumptions of the decoder will differ from those of the encoder. Misunderstandings can be avoided only by additional expenditure on checking. Either way, communication costs will vary with the economic, social and linguistic dissimilarities between regions. Transmission costs are partly accounted for by the terminal costs of the system, but there are other significant costs which are dependent on the distances involved. Thus the additional communication costs of an internal market will also depend on geographical factors such as distance.

This statement is a departure from the notion of the public good character of information, but their point can be salvaged if this characterization is claimed to be relative to other alternatives. Yet, it is here that the problem lies, for certainly these problems of coding and decoding pertain also to the sale and transfer of technology in the marketplace. That is, these costs should explain not only the limits of a given firm, but also its expansion when it is better at communicating knowledge within than across its boundaries.

The problem with the argument that the firm exists due to market failure is that it is overdetermined; the assumption of opportunism is not needed, only the differential in costs in the transmission of knowledge within the firm as opposed to between firms. If firms differ in their codes by which information is transferred, then it follows reasonably that they should differ in their capabilities to understand and apply knowledge. The cost of the transfer of technologies should differ among firms, and these differences should have an effect on the desirability to transfer technology within the firm or by license, independent of the issue of opportunism. Some firms are better at transferring specific kinds of technologies.

In current parlance, the costs of technology transfer are viewed as stemming from the degree of tacitness of the knowledge. In a seminal paper, Teece [1977] established that technology is not a public good, estimating the costs of transfer to range from $2 \%$ to $59 \%$ of total costs of the twenty-seven projects he analyzed. These costs declined with each subsequent transfer and with the experience of the recipient of the technology. None of these measures of costs was obviously related to transaction costs arising out of opportunism, such as legal fees or the dissipation of technology. Rather, 
these costs are derived from the efforts of codifying and teaching complex knowledge to recipients; more efforts must be expended, the less capable the user.

Largely, this distinction between differential capabilities and opportunism has been lost in the discussion of the internalization of markets for knowledge. Even when an appeal is made to the idea of knowledge as varying in tacitness and the cost of transfer, the argument is invariably tied to market failure. Following a discussion of knowledge as tacit and market failure, Teece [1983] writes that "the existence of firm specific rent-yielding assets which are non-tradeable for transaction cost reasons can be seen as providing a driving force for horizontal FDI" (p. 55).

The blurring of this distinction is especially clear in the recent writing on the transaction cost view of joint ventures. Thus, Hennart [1988: 365] expands now the notion of tacit knowledge (which was in the earlier 1982 book restricted to informational asymmetries within the firm) to encompass potential transactions in the market and why they are internalized. Markets appear to fail no matter if knowledge is a public good or tacit.

It should be noted that the instrumental factor is no longer information asymmetry, but only the common uncertainty over the value of the technology. There is, therefore, no necessity to link this uncertainty to opportunism so as to motivate why the market is internalized; rather, it is only necessary to conclude that the transfer of this technology can be expected to be carried out more economically inside a given firm.

This ambiguity appears also in the article by Hill, Hwang and Kim [1990] on entry choice. One motivation to transfer technology by joint venture or a wholly owned subsidiary is that the nature of the knowledge to be transferred is organizational and, therefore, requires an organizational vehicle by which to effect the transfer [Kogut 1988]. Hill, Hwang and Kim agree with this proposition and note that transferring technology to a less competent licensee results in lost revenues, that is, in opportunity costs, which they link to transactions costs [1990]. They write:

The licensee may lack the tacit know-how and informal routines that are required to turn a technological blueprint into a successful product.... Thus, by establishing a wholly owned subsidiary, the MNC can economize on the transaction costs of arm's-length contracting and earn greater rents from its technology. (pp. 117-28)

The concluding sentence on transaction costs is superfluous. If the MNC can make the transfer more efficiently, the choice of mode is fully motivated.

\section{KNOWLEDGE OF THE FIRM AND TECHNOLOGY TRANSFER}

How can we understand the implications of tacit knowledge for the theory of the firm without appealing to transaction costs and opportunism? To a large extent, the elements to this answer are apparent in the passages cited 
above. The starting point is the recognition that firms define a community in which there exists a body of knowledge regarding how to cooperate and communicate. These ideas are implicit in the discussion of codes by Buckley and Casson [1976] and Hennart [1982]. In our view, firms are efficient means by which knowledge is created and transferred. ${ }^{8}$ Through repeated interactions, individuals and groups in a firm develop a common understanding by which to transfer knowledge from ideas into production and markets. In this very critical sense, what determines what a firm does is not the failure of a market, but the firm's efficiency in this process of transformation relative to other firms. It is the difference in knowledge and the embedded capabilities between the creator and the users (possessed with complementary skills) which determine the firm boundary, not market failure itself. $^{9}$

One way to conceive of this knowledge is the distinction between information and know-how, which closely approximates the notions of declarative and procedural knowledge as used in artificial intelligence. Information is a factual statement, such as "inventory consists of 100 items." Know-how is a recipe describing how activities are carried out, such as "inventory is ordered when only 25 items remain." At the corporate level, it would be expressed in rules of informal and formal organizing, such as how to divisionalize product lines. It is not without significance that most writers emphasizing market failure have stressed asymmetries in information and have neglected differences in performance as determined by the stock of know-how. ${ }^{10}$

This distinction between information and know-how, though abstract, is not without direct significance in the context of technology transfer. Information is often provided in blueprints; yet even here, not all information may be identified or easily expressed. Know-how is transferred through manuals describing the requisite procedures or, as described in length by Hall and Johnson [1970] in their study on transfer of aircraft technology to Japan, by the exchange of engineers and workers to the new site.

Because knowledge is so often experiential in nature, it has the quality of being accumulated incrementally over time. Empirical studies of technology transfer clearly support the proposition that the characteristics of knowledge determine the costs and mode of transfer. One of the most persistent findings in work on technology transfer is the importance of prior experience. As cited earlier, Teece [1977] found that the principal determinants of transfer costs are the degree of previous experience with transferring the technology, the age of the technology, and the number of firms using similar technologies. These variables capture the direct experience with transferring the technology, understanding its use over time, and the common knowledge as to its properties.

Another way to understand these results is to tie them to a common latent factor involving the codification of knowledge. In other words, these variables are proxy measures of how tacit the underlying knowledge is. Since older technologies are often better codified, they are less costly to transfer. 
Experience with the technology again points to the important relationship between the current state of knowledge and learning capabilities of the adopter.

These issues are pertinent to a related but different question of whether the technology transfer is carried out within the firm or by license to a third party. Contractor [1981] found that technology transfer (via licensing) increases with the number of other firms using a technology, suggesting that spillovers can create a generalized and cumulative capability in its use. Davidson and McFetridge [1984] similarly found that transfer to unaffiliated recipients is promoted if the firm has transferred technology in the past. However, experience in internal transfers encourages more internal transfers in the future. These findings lend themselves to the interpretation that the experience in internal transfers is codified in a way idiosyncratic to the firm, but once a firm has invested in codifying knowledge for the purpose of licensing, external transfers are subsequently promoted.

There are, then, clear indications that the costs of transfer are related to the accumulation of experience and learning. The standardization of evaluation systems and procedures is an expression of the shared knowledge, values, and assumptions and eases the transfer of knowledge within the firm. But to the extent that a firm has developed procedures by which to codify knowledge for the benefit of external users, the more easily it should be able to transfer technology to unaffiliated parties.

\section{AN EMPIRICAL INVESTIGATION}

We can provide grounding for the above discussion by analyzing the effects of the attributes of knowledge on the decision whether to transfer technology within the firm or to third parties. The following investigation is meant to show that knowledge that is difficult to codify or teach and is also complex will tend to be transferred within the firm. This claim arises from our view that firms exist to create and transfer knowledge that is difficult to encode for the purposes of external dissemination.

For this purpose, we draw upon questionnaire data described in Zander [1991a,b] and Zander and Kogut [forthcoming]. The questionnaire was designed to measure the aspects of knowledge of the capability to manufacture an innovation. Following Rogers [1962] and Winter [1987], several scales measuring attributes of knowledge were developed. The constructs of codifiability, teachability, and complexity are chosen, as they are the aspects which can be most expected to influence the transfer of knowledge. ${ }^{11}$

Each index measuring attributes of knowledge was constructed from items derived from a questionnaire (see Appendix 1). For Codifiability, the items were designed to capture the extent to which the knowledge has been articulated in documents. This knowledge may be substantive, e.g., in blueprints, or it may be procedural, e.g., in a recipe for carrying out a task [Kogut and Zander 1992]. 
Teachability is designed to capture the ease by which know-how can be taught to new workers. ${ }^{12}$ As has been recognized, technology transfer often requires the sending of engineers and workers from the originating plant to assist in the building up of know-how in the sister plant. To the extent that this know-how is easily taught, the transfer is more feasible and can be expedited.

Complexity proved to be one of the more difficult scales to identify. We define complexity as the number of critical and interacting elements embraced by an entity or activity. As the knowledge being dimensionalized concerns manufacturing, we developed a variable by adding the scores on four items indicating the importance of four types of processes, as identified by Hayes and Wheelwright [1984]. The more complex a manufacturing technology, the more difficult it should be to transfer or to imitate.

These scales measure the latent construct of the tacitness of knowledge. In previous work, the extent to which a firm has developed an understanding of a technology and its transfer has been measured by the age of the technology and the number of times transferred in the past. (See, for example, Teece [1977]; Contractor [1981]; and Davidson and McFetridge [1984].) We include these additional two variables in our estimations, as it is unlikely that the three scales measuring codifiability, teachability, and complexity (or any set of measures) can fully specify the tacitness of technology.

These five variables (codifiability, teachability, complexity, age of the technology at the time of transfer, and the number of times transferred) are used to predict the choice of transferring the ability to manufacture within the firm or by license. The dependent variable is, thus, binary, taking a value of one if transferred to a wholly owned subsidiary, zero if transferred externally. The statistical estimation relies on a logit specification, similar to the study by Davidson and McFetridge. We expect codifiability and teachability to be negatively related to the choice of transfer to wholly owned subsidiaries; complexity should be positively related. As a secondary interest, we test the variables of the age and previous times transferred, as suggested by Teece and others, and predict a negative relationship to the choice of wholly owned subsidiaries.

We recognize that this test is by no means fully specified. In particular, we do not look at the capabilities of the recipient. The relationship between past use and ease of the transfer underscores the explanation advanced by Pavitt [1971] that the cumulative experience with a technology is a critical factor determining the learning capability of the recipient, as well as that of the firm possessing the technology. However important, it was not feasible to collect detailed data on the recipients.

\section{The Questionnaire}

The items and information regarding technology transfer were derived from a questionnaire instrument distributed to project engineers knowledgeable 
of the history of a major innovation. The innovations were identified from a study by Wallmark and McQueen [1986] on 100 major Swedish innovations. ${ }^{13}$ To satisfy the need to observe the history of the innovation over a long period and to question engineers familiar with this history, the sample was narrowed to those innovations occurring after 1960.

The respondents were selected by phoning the innovating firms, asking to talk to the technical director at the group level, and contacting one to five people having considerable knowledge of the product, the manufacturing process, and the transfer and imitation patterns. The technical directors recommended individuals (in nine cases the primary innovators) who were contacted by phone to prepare them for the questionnaire and to verify their knowledge. Multiple respondents for an innovation were not used, though, for some questionnaires, one individual scored the basic information and another answered the section dealing with the manufacturing process. (As the questions did not reflect on the respondent's performance, the risk of misattribution is low.) In the cases where an original innovator did not exist or was no longer accessible, individuals who were directly responsible for manufacturing and product management internationally were contacted. This process identified forty-four innovations from twenty firms. A response rate of $80 \%$ was attained; the remaining $20 \%$ were similar in size and industry affiliation to the responding organizations.

We acquired, consequently, questionnaire data regarding thirty-five innovations. (For a list of the innovations, years of their introduction and names of innovator firms, see Appendix 2.) The manufacturing of these innovations had been transferred eighty-two times to a foreign site; ${ }^{14}$ forty-one of these transfers were to wholly owned subsidiaries; the remaining forty-one were to joint ventures (twelve times), licensees (twenty-six), and by other kinds of contracts (three). The sample size of the tests thus consists of the eightytwo instances of the transfer of the capability to manufacture.

\section{Construction of the Measures}

The constructs derived from the questions (or items) in Appendix 1 were measured by forming scales derived from questions that were chosen a priori to contribute to each different construct. The scales were constructed by transforming the response into a standard normal deviate, with zero mean and variance of one; this transformation anchors the mean value of each item at zero and prevents the variance of any one item from driving the scale. Then, the standard scores were summed to form a scale score. In Table 1, the descriptive statistics for the variables are reported.

To test for reliability, Cronbach alphas were calculated for two of the scales, with the recommended .7 used roughly as a cutoff [Nunnally 1978]. ${ }^{15}$ Questions with low item-to-total correlation were deleted; reliabilities for the final constructs ranged from .678 to .785 . Discriminant validity could not be 
tested by factor analysis, but a comparison within and between correlations of the items indicated reasonably strong discrimination. ${ }^{16}$

\section{Results}

The results to the logit estimations are given in Table $2 . T$-statistics are given in parentheses; asterisks indicate the degree of significance using a two-tailed test. A positive sign means that an increase in the variable increases the probability of a transfer by an organizational mode; a negative sign indicates an increase in the probability of transfer by license or to a joint venture.

The results for the full model are given in column one of Table 2 . They consistently show that the more tacit the technology is, the more likely it will be transferred to a wholly owned subsidiary. The coefficients to the variables Codifiability and Teachability are negative and significant, indicating that as the knowledge becomes more codified and more easily taught, the more likely it will be transferred to a third party rather than to a wholly owned subsidiary. The positive coefficient to Complexity indicates that as technologies increase in their complexity, they are more likely to be transferred to wholly owned subsidiaries.

The results for the other two variables, drawn from the Teece study, are poor. The number of previous transfers is negatively related to transfer to wholly owned subsidiaries, contrary to expectation, but the relationship is insignificant. The effect of age of the technology is insignificant.

To show that these results are not spurious, we give the estimates for two more models. In column two, we estimate the effects of the three variables measuring tacitness on the choice of mode without the Teece variables; in column three, the effects of only the Teece variables are reported. The results are roughly the same. In short, it is reasonable to conclude that age and previous transfers act as proxies for a latent variable of tacitness; once more direct measures are provided, their influence should disappear.

We also partitioned the sample by grouping joint ventures and wholly owned subsidiaries together. The significance levels of the coefficients deteriorated. One explanation is simply that such a procedure grouped fifty-three cases of transfer into the joint venture/wholly owned category, and only twentynine into the licensing/contract choice; given the sample size, this imbalance may have affected the results. (The sample size of only twelve joint venture cases is too small for a multinomial specification.) A more persuasive, and interesting, explanation is that there is a qualitative difference in the knowledge among joint ventures and the partner firms. Joint ventures may be used as ways to transfer knowledge that is organizationally embedded and difficult to transfer by licensing [Kogut 1988]. Our results suggest, though, that there remains a distinguishable boundary in the knowledge between the partner firms. Knowledge is transferred by joint ventures, but for uncodified knowledge, the preferred vehicle is transfer between wholly owned units. 
TABLE 1

Descriptive Statistics

\begin{tabular}{llcc}
\hline & Variable Name & Mean & Standard Deviation \\
\hline 1 & Codifiability & 0 & 2.25 \\
2 & Complexity & 0 & 2.39 \\
3 & Teachability & 0 & 3.58 \\
4 & Number of Previous Transfers & 2.15 & 2.54 \\
5 & Age of Technology at Time of Transfer & 7.89 & 6.04 \\
\hline
\end{tabular}

\begin{tabular}{lrrrrr}
\multicolumn{5}{c}{ Correlation Matrix } \\
\\
\hline 1 & 1 & 2 & 3 & 4 & 5 \\
2 &.--10 & - & & & \\
3 & .02 & .46 & - & & \\
4 & -.06 & .05 & .02 & - & \\
5 & .01 & -.01 & -.05 & -.01 & -- \\
\hline
\end{tabular}

\section{OWNERSHIP ADVANTAGES AND KNOWLEDGE}

The above results provide support for the contention that firms specialize in the transfer of knowledge that is difficult to understand and codify. One interpretation of this result is that firms are able to transfer these technologies at a lower cost to wholly owned subsidiaries than to third parties. In this sense, the advantage of a firm is its relative efficiency in transferring idiosyncratic technologies. ${ }^{17}$

Another interpretation, rarely discussed in the literature, is that technologies that are difficult to codify also represent platforms for expansion into future markets. Because they are not well understood, they are resistant to rapid imitation. At the same time, novel technologies are likely to be less codified. Due to the joint qualities of novelty and difficult imitation, knowledge that is tacit can be expected to embody the advantage of the firm to grow and expand in the future. It is by recombining knowledge, resting upon what we have called a "combinative capability," that a firm exploits its current knowledge for expansion into new markets [Kogut and Zander 1992].

One important case of such recombining of knowledge is the expansion of the organizational boundaries of the firm into foreign markets. The evolutionary process of firm growth often proceeds by the establishment of exporting facilities to wholly owned operations. The initial entry serves in this regard as a platform that recombines the firm's knowledge acquired in its home market with the gradual accumulation of learning in the foreign market. In a final stage of this process, the learning from the foreign market is transferred internationally and influences the accumulation and recombination of knowledge throughout the network of subsidiaries, including the home market. 
TABLE 2

Logit Estimates of Effects of Independent Variables on the Choice of Wholly Owned Subsidiaries

\begin{tabular}{lccc}
\hline Variable Name & Model 1 & Model 2 & Model 3 \\
\hline Intercept & .37 & .01 & .25 \\
& $(.80)$ & $(.03)$ & $(.59)$ \\
Codifiability & -.32 & -.31 & \\
& $(-2.46)^{\star *}$ & $(-2.40)^{\star *}$ & \\
Complexity & .26 & .25 & \\
& $(2.14)^{\star *}$ & $(2.09)^{\star *}$ & \\
Teachability & -.21 & -.20 & \\
Number of Previous Transfers & $(-2.61)^{\star \star}$ & $(-2.60)^{\star *}$ & \\
& -.13 & & -.10 \\
Age of Technology at Time of Transfer & $(-1.37)$ & & $(-1.12)$ \\
& -.01 & & -.01 \\
& $(-.21)$ & & $(-.09)$ \\
Log Likelihood & -49 & -50 & -56 \\
& {$[P<.01]$} & {$[P<.01]$} & {$[.95>P>.05]$} \\
\hline
\end{tabular}

$t$ statistics in parentheses; two-tailed tests

${ }^{*} P<.10$

$\star * P<.05$

The above empirical results can be better understood in light of findings, given elsewhere, that the difficulty to codify and to teach knowledge increases the time to international transfer [Zander and Kogut forthcoming]. These findings are perfectly consistent with Teece's discovery that the costs of transfer vary widely. By our results, tacitness will increase the costs of transfer and decrease the speed by which knowledge is transferred within the firm or between partners. What firms do is to specialize in the creation and transfer of specialized knowledge.

That the transfer of knowledge is not trivial even within the firm is a fundamental observation. We can go further than this. In order to speed the internal transfer of knowledge relative to the speed of its diffusion or imitation by competitors, firms invest in ways to reduce the tacitness of technology by encoding its use and replications in rules and documentation. Competition among firms is based upon their differential capabilities, and their abilities to expand by the creation and replication of new knowledge faster than the imitative and innovative efforts of competitors.

The emphasis on the internalization of failed markets has curiously obscured the fact that the primary explanation for direct investment is the possession of an ownership advantage (or what we have called superior capabilities) responsible for the growth of the firm across international borders. ${ }^{18}$ The principal assumption has been that market imperfections, not ownership 
advantages, explain the boundaries of the firm. But is it not possible that the nature of the firm's advantage, as resting in the cooperative rules among employees, will influence its scope of activities?

Consider, for example, the statement by Buckley and Casson [1976: 69] on why their theory of direct investment is a more complete statement than the Hymer-Kindleberger theory of oligopolistic advantage:

Our theory provides a much more accurate and precise account of the origin of the attribute, or set of attributes, that give the MNE its advantages. We regard such advantages as the rewards for past investment in (i) $\mathrm{R}$ and $\mathrm{D}$ facilities which create an advantage in technological fields, (ii) the creation of an integrated team of skills, the rent from which is greater than the sum of the rewards to individuals, and therefore accruing to 'the firm' and within which individuals, as such, are dispensable, (iii) the creation of an information transmission network which allows the benefits of (i) and (ii) to be transmitted at low cost within the organization, but also protects such information, including knowledge of market conditions, from outsiders.... Our theory lays emphasis on the transmission of the ability to innovate.

These three points relegate the notion of market failure to a rather minimum role; point two and three map well, in fact, onto our distinction of know-how and information. But what is more important, the second point suggests a notion of team skills independent of individuals which is difficult to reconcile with a belief that internalization defines the boundary of the firm. For what determines, after all, the size of this team advantage? Why should it stop with only a small team instead of encompassing potentially large numbers of people cooperating through the application of organizing principles which are difficult to identify and imitate? Indeed, we can well imagine that one of the most potent reasons for maintaining the integrity of the firm across borders is the possession of higher order organizing principles (such as how to coordinate large multidivisional corporations) that are diffused across borders by an organizational extension called foreign direct investment. The point here is not that Buckley and Casson fail to recognize the link between ownership advantage, knowledge, and growth. Rather, the disagreement is with the belief that ownership advantage has no influence on what constitutes the firm. This belief is apparent in the important book put out by Casson [1987]. He writes:

Internalization theory represents an extension of the theory of choice to encompass the choice, within each market, of the appropriate contractual arrangement. Ownership advantage ... is not concerned with choice, but with the performance of the firm once managerial choices have been made. Its proper place is not within the subdivision of the theory that deals with choice, but within the subdivision that deals with the success, and the consequent growth, of the firm. (p. 36)

It is hard to imagine, however, how ownership advantage becomes the afterthought to decisions regarding what should be the contractual arrangements 
of the firm. There is a chicken and egg problem, which is unlikely to be clearly resolved in favor of one or the other.

What our propositions and empirical tests have sought to put forth is the view that the attributes of knowledge influence the decision of where to draw the boundaries of the firm. If we take seriously the notion that a firm specializes in the creation and transfer of new knowledge (or existing knowledge to new markets), then the important question becomes what is the firm's relative efficiency in carrying out these activities. An investigation of this issue requires a comparison of the capabilities of firms and the nature of the competitive market. It is not obvious that the answer will require a consideration of the failure of markets, no matter if this analysis is made from the perspective of positive theory or from a description of actual managerial practice.

\section{CONCLUSIONS}

Technology transfer lies at the heart of the issue of the growth of firms, domestically and internationally. Firms grow on their ability to create new knowledge and to replicate this knowledge so as to expand their market. Their advantage lies in being able to understand and carry out this transfer more effectively than other firms. Horizontal foreign direct investment is, therefore, the transfer of knowledge within the firm and across borders, and in this regard, such transfers are the primary expression of the growth of the firm. If the technology, however, has the quality of being general knowledge, then it can be expected that the replication of new knowledge can occur by other firms, either voluntarily through licensing, or through imitation.

Our study does not imply that internalization has no place in the theory of the multinational corporation. Markets, even if they rarely fail, are imperfect; human behavior can be motivated by self-interest. As a result, firms may decide to carry out activities internally even if they are not especially skilled in them. Yet, this observation explains why the boundaries of firms may extend beyond their strict advantage. It does, however, not rule out that the nature of this advantage itself has an important implication for the size and expansion of the firm.

There is an important caveat to this study. It is difficult to discuss and analyze the growth of the firm, and its boundaries, in the context of comparative statics. At any point in time, given the current stock of knowledge of the firm, managers will face the problem of deciding how to service a foreign market: by license, export, or direct investment. But it is difficult to believe that managers in a firm assess continuously at each point in time what will constitute the activities to be kept internally and which to divest. And surely, when such a decision is considered, an important aspect would be the extent to which a firm has an advantage in specialized knowledge of cooperating with agents and the extent to which their shared knowledge will further accumulate and provide platforms for future opportunities. 
In short, the decision to license is not simply based on the costs of this made relative to an internal transfer; it is also influenced by the expectation of revenues that would be foregone by failing to accumulate experiential knowledge in the foreign market. Common sense observations on business practices would seem to confirm that licensing to a foreign agent, because it does not lead to the acquisition of new knowledge by the licensing firm, is often regretted when that market opens up or grows rapidly. Knowledge acquired by using internal transfer to a subsidiary might in cases like this be useful for future introduction of other technologies and products.

We have suggested that the appropriate way to analyze the value of acquiring and recombining knowledge is, technically, by treating the "combinative capability" of the firm as an option, or platform, on future markets. ${ }^{19}$ To be able to compete in a country in the future may require, at a cost, learning how to manage operations and sales in a new environment. The sequential expansion of a firm's activities after the first entry into a country is an expression of the evolutionary acquisition and recombination of knowledge. In its more advanced evolution, this process alters the global knowledge of the firm and may result in its transformation towards a network of subsidiaries characterized by the cross-border transfer of learning. ${ }^{20}$

In this sense, the view that we put forth is compatible with an evolutionary perspective on the growth of the firm. Firms compete on the basis of the superiority of their information and know-how, and their abilities to develop new knowledge by experiential learning. The limiting factor on their growth is not only the competitiveness of other firms and the demand of the market, but also the extent to which their advantage can be replicated more quickly by themselves than through imitation by competitors. ${ }^{21}$ Our findings suggesting that firms specialize in the transfer of relatively tacit and idiosyncratic knowledge are consistent with this broader evolutionary perspective. 


\section{APPENDIX 1 \\ The Constructs and Variables}

CODIFIABILITY: Perceived Codifiability

1. A useful manual describing our manufacturing process can be written.

2. Large parts of our manufacturing control are embodied in standard type software that we modified for our needs.

3. Large parts of our manufacturing control are embodied in software developed within our company exclusively for our use.

4. Extensive documentation describing critical parts of the manufacturing process exists in our company.

Coefficient alpha: .678

TEACHABILITY: Perceived Teachability

1. New manufacturing personnel can easily learn how to manufacture the product by talking to skilled manufacturing employees.

2. New manufacturing personnel can easily learn how to manufacture our product by studying a complete set of blueprints.

3. Educating and training new manufacturing personnel is a quick, easy job.

4. New manufacturing personnel know enough after a normal high school education to manufacture our product.

5. New manufacturing personnel know enough after vocational training to manufacture our product.

Coefficient alpha: .785

\section{COMPLEXITY: Different Types of Manufacturing Processes}

How important are the following to manufacturing:

1. Processes for changing physical characteristics of a material (for example: chemical reactions, refinement, heat treatment).

2. Processes for changing the shape of material (for example: casting, pressing, rolling, bending).

3. Processes for giving materials certain dimensions (for example: turning, milling, drilling, sawing).

4. Processes for assembling different parts to a whole (for example: welding, soldering, gluing, screwing). 


\section{APPENDIX 2}

\section{List of Innovations}

1. Exchangeable Inductor for Steel Melting 1960 (ASEA)

2. Pressductor 1960 (ASEA)

3. Emulsified Fats for Intravenous Injection: INTRALIPID 1960 (KABI VITRUM/ STATSFORETAG)

4. Rail-Bound Hauling Car for Mines 1961 (HAGGLUND \& SONER)

5. Rubber Details for Rotating Drums 1961 (SKEGA/INCENTIVE)

6. Milk Sterilizer 1961 (ALFA-LAVAL)

7. Machine for Fluidized Freezing of Foodstuffs: FLOFREEZE 1961 (FRIGOSCANDIA CONTRACTING/AGA)

8. Quintus Type Steel Press for Use in the ASEA-STORA Process 1962 (ASEA)

9. Air-Cushioned Lawn Mower 1963 (ELECTROLUX)

10. Cross Cable 1963 (ERICSSON)

11. Matrix Printer 1964 (FACIT/ELECTROLUX)

12. Beta-Blocker: APTIN 1965 (HASSLE/ASTRA)

13. Pulp Dryer with Airborne Pulp Web: Type FC 1966 (FLAKT/ASEA)

14. Drug for Expansion of Bronchi: BRICANYL 1966 (DRACO/ASTRA)

15. Thyristor-Controlled Spin Control System for Locomotives 1967 (ASEA)

16. Isostatic Press for Steel Processing 1967 (ASEA)

17. Explosive: DYNAMEX 1967 (NITRO NOBEL)

18. Gel for Filtering: CNBr-Method 1967 (PHARMACIA/FORTIA)

19. High Resolution Copying Machine: MULTINEX 1968 (MISOMEX/INCENTIVE)

20. Ball Bearing: HUB 31969 (SKF)

21. Ore Transporter: HAGGLOADER 1969 (HAGGLUND \& SONER/ASEA)

22. Flash Dryer for Pulp 1969 (FLAKT/ASEA)

23. Semi-Synthetic Penicillin: PENGLOBE 1970 (ASTRA)

24. Selective Beta-Blocker: SELOKEN 1970 (HASSLE/ASTRA)

25. Roller Bearing: CC 1972 (SKF)

26. Ventilation System: OPTIVENT 1972 (FLAKT/ASEA)

27. Ignition Mechanism for Explosives: NONEL 1972 (NOBEL)

28. Machine for Feeding Metal Sheets: DOPPIN-FEEDER 1972 (VOLVO)

29. Ventilation System: DIRIVENT 1974 (FLAKT/ASEA)

30. High Temperature Steel 153 MA \& 253 MA 1974 (AVESTA JERNVERK/NORDSTJERNAN)

31. Chemical for Wound Treatment: DEBRISAN 1975 (PHARMACIA/FORTIA)

32. Hydraulic Rock Drill 1975 (ATLAS COPCO)

33. Telephone Switching System: AXE 1976 (ELLEMTELIERICSSON)

34. Stainless Steel: 245 SMO 1976 (AVESTA)

35. Self-Emptying Railway Car for Ore 1978 (LKAB)

\section{NOTES}

1. The seminal work on an evolutionary theory of the firm is obviously Nelson and Winter [1982]. See Kogut and Zander [1992] and Kogut [forthcoming] for the expansion of these ideas in the context of firm knowledge in general and the evolution of the multinational corporation, respectively.

2. See Dunning [1977] for the original statement of ownership, location, and internalization advantages. Firm-specific advantage has been discussed by Rugman [1981].

3. There are obviously other advantages, such as the monopoly ownership of raw materials. We concentrate on those advantages that can be considered as giving the superior capability to do something, such as innovate or advertise.

4. Caves clearly recognizes this point in his textbook, where he states the standard reasons for market failure [1982: 4ff]. There is also a third condition (as explicit in Dunning's [1977] eclectic theory) of 
location. According to Caves [1971:5], "the general positive reason favoring the service to a market by local production is some complement between such production and the rents attainable from local sales."

5. By public good, it is meant that one party may enjoy the use of a common good (such as the rose bush planted on the property of the other party) without diminishing its availability to the other. The issue of market failure arises out of a problem whether the owner of the rose can "appropriate" a pecuniary payment from the neighbor.

6. Of course, this argument is one among many given by Buckley and Casson as a motive for internalization. It should be noted that the concept of internalization is much more broad than the notion of "transaction costs" by Williamson [1975], as the latter does not exclude the case of market power considerations.

7. Though we focus on the internalization school of thought, it can be noted that Williamson does not fare much better in consistency in this regard. In his 1975 book, he appealed to the quasi-morality of the firm without definition; Hennart spells out a consistent logic concerning why this morality arises from better information in the context of opportunism.

8. The following is discussed at length in Kogut and Zander [1992]. Our line of reasoning is indebted to Pavitt [1971] where the two factors of technological capability and experience were joined for the understanding of the multinational corporation.

9. See also Buckley [1983: 39-40].

10. As an illustration, consider the difficulty of reading a text on theoretical physics; the same information is available to all readers, but the capability of interpretation varies.

11. See, for example, the discussion of Hall and Johnson [1970] and Teece [1977]. We leave out observability, because it is highly correlated with these measures. See Zander [1991b] for a discussion.

12. With reference to the questionnaire items 4 and 5 in the Appendix, it should be observed that high school education and vocational training are alternative ways of education, one of which is chosen by students at the age of 16 .

13. Wallmark and McQueen defined innovations as new technological products or methods that have been commercialized in Sweden by innovators living in Sweden. Major innovations were chosen on the basis of generated annual turnover, with U.S. $\$ 3.5$ million serving as the cutoff, and the presence of a patent and positive revenue growth serving as additional criteria. The purpose was to identify the type of innovations that constituted the foundation on which large Swedish MNCs like SKF, Electrolux, Ericsson, ASEA, Sandvik, Alfa-Laval, Nitro Nobel, Atlas Copco, and Tetra Pak were built.

14. Reflecting the trade and investment pattern of Swedish firms, the most important recipient countries were the U.S.A. (nine transfers), Canada (seven), France (seven), Australia (seven), Japan (six), England (four), and Norway (four).

15. For Complexity, we a priori stipulated the items to be used in the scale as the sum of the importance of various processes to manufacturing. There is no reason to expect these items to be correlated.

16. The validation of the questionnaire design and the reliability and validity of the constructs are discussed in detail in Zander [1991a] and Zander and Kogut [forthcoming].

17. An interpretation contrary to the one we propose is that complexity and asset specificity are related. Complexity in knowledge leads to asset specificity (that is, a party to the transaction cannot easily exit the relationship), and asset specificity, by the arguments given in Williamson [1979], leads to market failure and hence to what the direct investment literature calls internalization. For our study, we would have to believe that potential licensees refuse to purchase a complex technology because complexity is likely to lead to greater asset specificity. We find this argument unconvincing. First, while others have previously found a positive relationship between complexity and internalization (see Masten [1984]), it is important to note that the label "complex" is not standardized and the measurement of complexity varies by author. We have defined our complexity construct to reflect the degree to which different disciplinary knowledge must be combined, which is in accordance with theoretical concerns, and the relationship of our construct to asset specificity is tenuous. Second, this argument still ignores the finding of the significance of codifiability in our study.

18. As Casson [1987] has explained, internalization of markets can be a sufficient explanation of direct investment, as in the arbitrage of imperfect markets due, for example, to differential taxation of profits.

19. See Kogut and Zander [1992] and Kogut [1992] for a link between this notion of combinative capabilities and the options, or platforms, to expand in the future. 
20. We know from Stopford and Wells [1972] and Dyas and Thanheiser [1976] that firms expand overseas on the basis of their organization structure designed for competing in the home market. A common observation is that the MNC does not adapt its technology significantly to the foreign markets. We are thus not surprised that foreign direct investment is the extension of organizing principles (which constitute the firm's knowledge) to new markets. Not always is this knowledge entirely well understood, which leads to different experiments in different countries. The results of these experiments will over time be disseminated in the "multinational network".

21. See Nelson and Winter [1982] for models along these lines.

\section{REFERENCES}

Arrow, Kenneth. 1974. The limits of organization. New York: W.W. Norton.

Buckley, Peter \& Mark Casson. 1976. The future of multinational enterprise. London: Macmillan and Co.

1983. New theories of international business: Some unresolved issues. In Mark Casson, editor, The growth of international business. London: Allen and Unwin.

Casson, Mark. 1987. The firm and the market. Cambridge, Mass.: MIT Press.

Caves, Richard E. 1971. International corporations: The industrial economics of foreign investment. Economica, 38: 1-27.

1982. Multinational enterprise and economic analysis. Cambridge, U.K.: University of Cambridge.

Contractor, Farok. 1981. International technology licensing: Compensation, costs and negotiations. Lexington, Mass.: Lexington Books.

Davidson, William \& Donald McFetridge. 1984. International technology transactions and the theory of the firm. Journal of Industrial Economics, 32: 253-64.

Dunning, John. 1977. Trade, location of economic activity and the multinational enterprise: A search for an eclectic approach. In B. Ohlin, P.O. Hesselborn \& P.M. Wijkman, editors, The international allocation of economic activity. London: Macmillan.

Dyas, Gareth P. \& Hans T. Thanheiser. 1976. The emerging European enterprise: Strategy and structure in French and German industry. London: Macmillan.

Hall, G. \& R. Johnson. 1970. Transfers of United Aerospace Technology to Japan. In Raymond Vernon, editor, The technology factor in international trade. New York: Columbia University Press.

Hayami, Y. \& V. Ruttan. 1971. Agricultural development and international perspective. Baltimore: Johns Hopkins.

Hayes, Robert \& Steven Wheelwright. 1984. Restoring our competitive edge-Competing through manufacturing. New York: John Wiley and Sons.

Hennart, Jean-François. 1982. A theory of the multinational enterprise. Ann Arbor, Mich.: University of Michigan.

1988. A transaction costs theory of equity joint ventures. Strategic Management Journal, 9: 361-74.

Hill, Charles, Peter Hwang \& Wi Chan Kim. 1990. An eclectic theory of the choice of international entry mode. Strategic Management Journal, 11: 117-28.

Hymer, Stephen. 1976. The international operations of national firms: A study of direct investment. Cambridge, Mass.: MIT Press (reprint of Ph.D. thesis, Department of Economics, MIT, 1960).

Johnson, Harry. 1970. The efficiency and welfare implications of the multinational corporation. In Charles Kindleberger, editor, The international corporation. Cambridge, Mass.: MIT Press.

Kogut, Bruce. 1988. Joint ventures: Theoretical and empirical perspectives. Strategic Management Journal, 9: 319-32.

1992. An evolutionary perspective on the multinational corporation. In D. Nigh \& B. Toyne, editors, International business inquiry: An emerging vision. Columbus, S.C.: University of South Carolina.

\& Udo Zander. 1992. Knowledge of the firm, combinative capabilities, and the replication of technology. Organization Science, 3: 383-97. 
Magee, Stephen. 1977. Information and the multinational corporation: An appropriability theory of foreign direct investment. In Jagdish N. Bhagwati, editor, The new international economic order. Cambridge, Mass.: MIT Press.

Masten, Scott. 1984. The organization of production: Evidence from the aerospace industry. Journal of Law and Economics, 27: 403-18.

McManus, J. 1972. The theory of the international firm. In G. Paquet, editor, The multinational firm and the nation state. Ontario, Can.: Collier Macmillan Canada.

Nelson, Richard \& Sidney Winter. 1982. An evolutionary theory of economic change. Cambridge, Mass.: Harvard University.

Nunnally, John C. 1978 (second edition). Psychometric theory. New York: McGraw Hill.

Pavitt, Keith. 1971. The multinational enterprise and the transfer of technology. In John Dunning, editor, The multinational enterprise. London: George Allen and Unwin.

Rogers, Everett. 1962. Diffusion of innovations. New York: Free Press.

Rugman, Alan. 1980. Internalization as a general theory of foreign direct investment: A re-appraisal of the literature. Weltwirtschaftliches Archiv, 116: 365-79.

1981. Inside the multinationals: The economics of internal markets. New York: Columbia University Press.

Stopford, John M. \& Louis T. Wells. 1972. Managing the multinational enterprise: Organization of the firm and ownership of subsidiaries. New York: Basic Books.

Teece, David. 1977. Technology transfer by multinational firms: The resource costs of transferring technological know-how. Economic Journal, 87: 242-61.

1983. Technological and organizational factors in the theory of the multinational enterprise. In Mark Casson, editor, The growth of international business. London: George Allen \& Unwin.

Wallmark, Torsten \& Douglas McQueen. 1986. 100 viktiga svenska innovationer under tiden 19451980. Lund, Swe.: Studentlitteratur.

Williamson, Oliver. 1975. Markets and hierarchies: Analysis and anti-trust implications. New York: Free Press.

1979. Transactions-cost economics: The governance of contractual relations. Journal of Economics and Organization, 22: 3-61.

Winter, Sidney. 1987. Knowledge and competence as strategic assets. In David Teece, editor, The competitive challenge - Strategies for industrial innovation and renewal, 159-84. Cambridge, Mass.: Ballinger.

Zander, Udo. 1991a. Exploiting a technological edge-Voluntary and involuntary dissemination of technology. Stockholm: Institute of International Business.

1991b. International transfer of manufacturing technology_Patterns and determinants in Swedish MNCs. Stockholm: Institute of International Business, Mimeo, Research Paper 91/2.

\& Bruce Kogut. Knowledge of the firm and the speed of the transfer and imitation of organizational capabilities: An empirical test. Organization Science, forthcoming. 